\title{
Adherence to emergency department discharge prescriptions
}

\author{
Corinne M. Hohl, MD, MHSc;

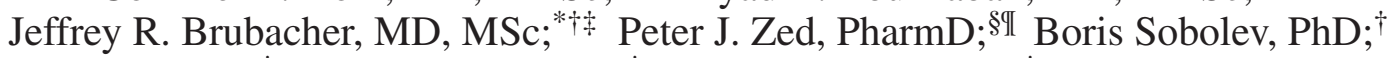 \\ Gina Tsai, BPharm; ${ }^{\dagger}$ Patricia Kretz, BSc $;^{\dagger}$ Kevin Nemethy, MD $;^{\dagger}$ Jan Jaap Bijlsma, MD; $;^{* \dagger}$ \\ Roy A. Purssell, MD*ं
}

\begin{abstract}
Objective: Nonadherence to prescribed medication is associated with increased morbidity and mortality as well as the increased use of health services. The main objective of our study was to assess the incidence of prescription-filling and medication adherence in patients discharged from the emergency department (ED).

Methods: This was a prospective, observational study carried out at a Canadian tertiary care ED with an annual census of 69000 . We enrolled a convenience sample of patients being discharged with a prescription. We queried a provincial prescription-dispensing database 2 weeks later to determine whether prescriptions had been filled. We used a standardized follow-up interview to assess adherence and whether or not the patient experienced an adverse drug-related event (ADRE) or an unplanned revisit to an ED or clinic.

Results: Of the 301 patients who agreed to participate, follow-up was successful for 258 (85.7\%). Fifty-one patients (19.8\%, 95\% confidence interval [Cl] 15.4\%-25.1\%) failed to fill their discharge prescriptions and $104(40.3 \%, 95 \% \mathrm{Cl} 34.5 \%-46.4 \%)$ did not adhere to 1 or more medications. Antibiotics were associated with a lower odds ratio (OR) of nonadherence (OR $0.21,95 \% \mathrm{CI}$ 0.08-0.52). There was a trend toward increasing nonadherence in patients who reported an ADRE (OR $1.84,95 \% \mathrm{Cl} 0.98-3.48$ ) or had 2 or more medications coprescribed (OR $1.71,95 \% \mathrm{Cl}$ 0.95-3.09). There was also a trend toward a higher risk of a revisit to an ED or clinic in nonadherent patients (OR $1.75,95 \% \mathrm{Cl} 0.94-3.25)$.

Conclusion: Approximately 4 in 10 patients discharged from the ED did not adhere to his or her prescribed medication. Our results suggest that patients who are prescribed antibiotics are more likely to be adherent, and that further evaluation of the associations between nonadherence, ADREs, the coprescription of 2 or more medications and the use of health services is warranted.
\end{abstract}

Keywords: adherence, compliance, adverse drug-related events, return visits, health services use, emergency medicine

RÉSUMÉ

Objectif : La non-observance médicamenteuse est associée à une hausse de la morbidité, de la

From the *Department of Emergency Medicine, Vancouver General Hospital, Vancouver, BC, the HFaculty of Medicine, University of British Columbia, Vancouver, BC, the $\neq$ Centre for Clinical Epidemiology \& Evaluation, Vancouver Coastal Health Research Institute, Vancouver, BC, the §Department of Pharmacy, Queen Elizabeth II Health Sciences Centre, Capital Health, Halifax, NS, and the ๆDepartment of Emergency Medicine and College of Pharmacy, Dalhousie University, Halifax, NS

Submitted Dec. 11, 2007; Revised May 3, 2008; Accepted Jun. 23, 2008

This article has been peer reviewed.

CJEM 2009;11(2):131-8 
mortalité et de l'utilisation des services de santé. L'objectif principal de notre étude était d'évaluer l'incidence des ordonnances exécutées par les patients et l'observance médicamenteuse chez les patients après leur départ de l'urgence.

Méthodes: Nous avons réalisé cette étude prospective d'observation dans un service d'urgence d'un centre de soins tertiaires au Canada, dont la clientèle annuelle est de 69000 personnes. Nous avons recruté un échantillon de commodité de patients ayant obtenu une ordonnance à leur congé de l'urgence. Nous avons interrogé une base de données provinciale sur la dispensation des ordonnances 2 semaines plus tard pour déterminer si les patients avaient fait remplir leur ordonnances. Nous avons réalisé des entretiens de suivi standard pour évaluer l'observance médicamenteuse et déterminer si le patient avait eu des effets indésirables des médicaments (EIM) ou s'il avait fait une visite imprévue subséquente à l'urgence ou à la clinique.

Résultats : Parmi les 301 patients qui ont accepté de participer à l'étude, nous avons pu faire un suivi auprès de 258 patients $(85,7 \%)$. Cinquante et un patients $(19,8 \%)$ [intervalle de confiance (IC) à $95 \%$ de 15,4 à 25,1\%] n'ont pas fait remplir leurs ordonnances, et $104(40,3 \%$, IC à $95 \%$ de 34,5 à $46,4 \%$ ) patients ayant une ordonnance pour 1 ou plusieurs médicaments ne respectaient pas leur traitement médicamenteux. Les antibiotiques étaient associés à un ratio d'incidence approché (RIA) moindre de non-observance ( $R I A=0,21, I C$ à $95 \%$ de 0,08 à 0,52 ). Nous avons constaté une tendance à la hausse de la non-observance chez les patients ayant signalé un EIM (RIA = 1,84, IC à $95 \%$ de 0,98 à 3,48) ou ceux pour qui 2 médicaments ou plus avaient été coprescrits ( $\mathrm{RIA}=1,71, \mathrm{IC}$ à $95 \%$ de 0,95 à 3,09). Il émergeait aussi une tendance quant au risque plus élevé d'une visite subséquente à l'urgence ou à une clinique chez les patients non observants $(\mathrm{RIA}=1,75 ; \mathrm{IC}$ à $95 \%$ de 0,94 à 3,25).

Conclusion : Environ 4 patients sur 10 n'ont pas respecté le traitement médicamenteux prescrit à leur sortie de l'urgence. Nos résultats suggèrent que les patients à qui l'on prescrit des antibiotiques sont plus susceptibles de respecter leur traitement médicamenteux. Nous sommes d'avis que d'autres études sur le lien entre la non-observance médicamenteuse, les EIM, la coprescription de 2 médicaments ou plus et l'utilisation des services de santé s'imposent.

\section{Introduction}

Adherence describes the extent to which a patient follows an agreed-on mode of treatment recommended by a health care professional with limited or no supervision. ${ }^{1}$ Nonadherence to prescription medication is a problem because it limits the effectiveness of therapeutic interventions and has been linked to higher morbidity and mortality as well as the higher use of health services..$^{2-8}$ Because of its impact on health outcomes, understanding the epidemiology and determinants of nonadherence is important.

Previous studies on adherence to emergency department (ED) discharge medications have estimated that 7\%-35\% of ED patients fail to fill discharge prescriptions ${ }^{9-12}$ and that $6 \%-31 \%$ report being nonadherent. ${ }^{13,14}$ These estimates may not be applicable to the Canadian adult ED context, as these studies investigated children, ${ }^{9,10}$ were performed in managed care settings, ${ }^{9,12}$ or may have underestimated the proportion of nonadherent patients because of a Hawthorne effect or recall bias. ${ }^{10-14}$

The primary objective of our study was to assess the incidence of prescription-filling and adherence in patients who were discharged from a large Canadian tertiary care ED. Secondary objectives were to compare self-reported prescription-filling with prescription-filling information determined from a provincial pharmacy database, and to examine factors associated with prescription-filling and nonadherence.

\section{Methods}

\section{Study design and setting}

This prospective observational study enrolled patients between Jun. 13, 2005, and Aug. 2, 2005, who were discharged from the ED of Vancouver General Hospital, a Canadian tertiary care, university teaching centre with an annual ED census of 69000 patients.

The institutional ethics review board approved the research protocol and authorized the use of deceptive consent in which the purpose of the study was concealed from participants.

\section{Inclusion and exclusion criteria}

We enrolled patients who were over 18 years of age, spoke English and were discharged from the ED with a prescription written or cosigned by an attending emergency physician (EP). We excluded those patients who had been transferred from or to another health care facility, were triaged 
at acuity levels 1 or 2 (emergent or urgent) on the Canadian Emergency Department Triage and Acuity Scale, ${ }^{15}$ were in distress, presented with an intentional overdose, were unable to sign their name or understand the purpose of the study, left against medical advice, had previously been enrolled, were seen by a consultant or admitted to hospital, had no phone or lived outside the study province.

\section{Patient enrolment}

An administrative database was used to determine the proportion of patients who were discharged from our ED during each hour of the day, by day of the week. Data collection shifts were scheduled to mirror the ED patients' discharge patterns so that a representative sample could be collected. Data collection shifts were allocated according to research assistant (RA) availability.

At the beginning of each data collection shift, RAs used the hospital's computerized patient tracking system to identify all patients in the ED. They approached patients consecutively according to the time of registration after they had been triaged and were waiting to see the EP. Research assistants next approached patients who had been seen by the EP and were waiting for a disposition decision. Patients were given consent forms and asked to return the signed forms upon discharge if they wished to participate. The consent form stated that the purpose of the study was “... to learn more about which medications you are given in the emergency department and which ones you are given to take at home ... [to understand] whether or not you experience any new health problems or problems with medications in the next two weeks." In addition, EPs paged RAs before giving patients discharge prescriptions in order to enable the RA to collect the consent form before the patient left.

\section{Data collection}

Patients were asked to complete pilot-tested, standardized data collection forms to obtain information on demographics, socioeconomic status, insurance coverage beyond the provincial drug plan, illicit drug use, access to a family physician and complementary and alternative medication use. Research assistants subsequently verified all the information with patients before they were discharged and recorded the chief complaint and discharge diagnosis. Baseline prescription medication use was obtained through PharmaNet, a provincial prescription database that captures all prescriptions filled in community pharmacies. Discharge prescriptions were recorded before patients left the ED.

Each patient's account in the provincial prescription database was searched 2 weeks later. Provincial health numbers were used to link to individual patient accounts to determine whether prescriptions had been filled. Prescription-filling was defined as the purchase of the medication within 2 weeks of the index visit based on the provincial prescription database.

Research assistants then made up to 5 attempts to reach patients by telephone. They asked patients whether they had filled their prescription, and then asked them to perform and report a pill count, which was used to determine adherence status. Adherence was determined according to whether or not the medication had been prescribed as a regular or as-needed dosage (Box 1). In defining adherence to as-needed medication, we sought to incorporate patients' perceptions of disease as well as their judgments about whether or not medication was necessary. For example, a patient who was prescribed oxycodone on an asneeded basis could be deemed adherent without taking any medication at all if the condition improved to the point where the patient felt that no further tablets were needed,

Box 1. Definitions of adherence to prescription medication

Regular medication

- Having filled all prescriptions within 2 weeks of the index visit

AND

- Having reported ingestion of $\geq 80 \%$ of all intended doses of all medications by the time of follow-up*

As-needed medication

- Having filled all prescriptions within 2 weeks of the index visit

AND

- EITHER having taken

- $\quad \geq 80 \%$ of intended dosest for each discharge medication, OR

- $\quad<80 \%$ of doses of all discharge medications, but reported that the indicating condition improved before finishing the prescription(s), OR

- $\quad<80 \%$ of doses for each medication, but reported that the medication(s) was/were effective, did not produce side effects and filled no other prescription replacing the discharge medication(s)

- $\quad$ Not having filled $\geq 1$ prescription(s)

AND

- Having reported that the indicating condition improved before filling the prescription(s)

Sensitivity analysis

- $\quad$ Not having filled $\geq 1$ prescription(s)

AND

- Having obtained the prescription(s) from another source $\ddagger$ and having taken $\geq 80 \%$ of doses, or less if the condition improved

*As reported by the pill count at the 2-week telephone follow-up. tWhen calculating the percent of doses taken, the maximal allowed dose was used as denominator.

¥Friend, family member, another third party or from a previous prescription. 
or without taking $80 \%$ of the intended doses if the condition had not improved but the patient found the tablets effective, free of adverse effects and had not sought a replacement.

A standardized algorithm was used to determine whether the patient had experienced an adverse drug-related event (ADRE), defined as an unfavourable medical event related to the use or misuse of medication. ${ }^{16}$ Both the onset and resolution of symptoms had to occur within a plausible time frame after having started and stopped the medication. The symptom could not be explained by an underlying medical condition and had to be consistent with a known toxic effect, drug interaction, withdrawal reaction or any adverse event from error or nonadherence as listed in the Compendium of Pharmaceuticals and Specialties. ${ }^{17,18}$ A single investigator (C.H.) reviewed all cases in which the patient was believed to have suffered an ADRE, and consensus between the RA and the investigator, based on the criteria above, was required for an event to be deemed an ADRE.

An unplanned visit was defined as any return to an ED, clinic or physician's office within 2 weeks that had not been planned at the time of discharge. Unplanned ED visits and admissions to the study hospital were determined from the hospital's computerized admission, discharge and transfer database. Other unplanned visits were specifically inquired about at the time of telephone follow-up.

\section{Data analysis}

Data were entered into a Microsoft Excel (Microsoft Corp.) database by a single RA and verified by a second RA. Descriptive statistics were reported as means or proportions with 95\% confidence intervals (CIs). In estimating the proportion of nonadherent patients, we performed a sensitivity analysis in which patients who were prescribed as-needed medications were considered adherent even if they did not fill their prescriptions and did not report resolution or improvement of their condition, provided they took medications from a previous prescription or obtained them from a third party (Box 1).

Potential predictor variables for prescription-filling and nonadherence were identified by consultation with experts in the field and a literature review, ${ }^{9-14}$ and were established a priori. We selected variables for entry into the multivariate regression model by excluding variables with $5 \%$ or more of values missing, and excluding colinear variables identified by Pearson $\chi^{2}$ testing using a $p$ value cut-off of 0.05 . The associations between prescription-filling and predictor variables, and nonadherence and predictor variables were measured using odds ratios (ORs) with 95\% CIs. Regression analyses were conducted for both patientlevel and medication-level outcome variables, and were modeled with a minimum of 10 events per covariate (Table 1, Table 2). Data were analyzed using SAS Version 9.1.3 for Windows (SAS Institute, Inc.).

A sample size calculation suggested that 320 patients would be required to detect an estimated proportion of nonadherence of $30 \%$ with a $95 \%$ CI of no larger than $25 \%-35 \%$.

\section{Results}

We screened 1965 patients and, of those, 301 consented and were discharged with a prescription (Fig. 1). These patients were prescribed 225 regular medications and 180 asneeded prescription medications. Telephone follow-up was successful for 258 patients (85.7\%). Discharge diagnoses and prescriptions were similar between patients who were followed up and those lost to follow-up. However, among individuals lost to follow-up, a higher proportion of patients were in the lowest income bracket or reported using illicit drugs (Table 3).

Table 1. Crude and adjusted odds ratios of patient factors associated with nonadherence*

\begin{tabular}{llccr} 
Variable & \multicolumn{1}{c}{ Comparison } & Crude OR (95\% Cl) & Adjusted OR (95\% Cl) & $p$ value \\
\hline Age $>60 \mathrm{yr}$ & Age $<60 \mathrm{yr}$ & $0.84(0.45-1.57)$ & $0.96(0.49-1.90)$ & 0.92 \\
Female & Male & $0.74(0.44-1.24)$ & $0.78(0.45-1.34)$ & 0.36 \\
Insurance & No insurance & $0.90(0.54-1.52)$ & $0.86(0.49-1.49)$ & 0.58 \\
Followed by a GP & Not followed by a GP & $0.65(0.35-1.20)$ & $0.68(0.35-1.33)$ & 0.26 \\
Herbals & No herbals & $0.57(0.32-1.04)$ & $0.64(0.35-1.18)$ & 0.15 \\
$\geq 2$ medications prescribed & 1 medication prescribed & $1.82(1.03-3.20)$ & $1.71(0.95-3.09)$ & 0.08 \\
ADRE & No ADRE & $1.80(0.98-3.32)$ & $1.84(0.97-3.48)$ & 0.06 \\
Unplanned visit & No unplanned visit & $1.64(0.91-2.96)$ & $1.75(0.94-3.25)$ & 0.09 \\
\hline
\end{tabular}

$\mathrm{ADRE}=$ adverse drug-related event; $\mathrm{Cl}=$ confidence interval; $\mathrm{GP}=$ general practitioner; $\mathrm{OR}=$ odds ratio.

*The variables education, employment status, receipt of paycheque within 2 weeks, income level, insurance status and availability of transportation to a pharmacy were strongly correlated. A correlation matrix was created to ensure that only noncorrelated variables were entered into the model

simultaneously. Variable selection for entry into the final model was guided by missing values and associations with nonadherence that had been reported previously in the literature. .14 $^{-14}$ 


\section{Prescription-filling}

The proportion of patients who self-reported that their prescriptions had been filled was $225 / 258(87.2 \%, 95 \%$ CI $82.6 \%-90.7 \%)$ compared with $207 / 258$ (80.2\%, $95 \%$ CI $74.9 \%-84.6 \%$ ) from the provincial prescription database (a difference of $7.0 \%, 95 \%$ CI $0.6 \%-13.3 \%, p=0.03$ ). Among patients who were lost to follow-up, 29/43 (67.4\%, 95\% CI 52.4\%-79.5\%) did not fill 1 or more prescriptions (a difference of $-12.8 \%, 95 \%$ CI $-27.6 \%$ to $2.0 \%$ ). The most common reasons cited for not filling prescriptions are listed in Table 4. Multivariate regression modeling indicated that there was no association between prescriptionfilling and age, socioeconomic variables, complementary and alternative medication use, illicit drug use and the time of presentation. A medication level analysis did not reveal any association between medication class and the odds of filling the prescription.

\section{Adherence}

Among the 258 patients for whom follow-up was successful, 104 were nonadherent with 1 or more medications $(40.3 \%, 95 \%$ CI $34.5 \%-46.4 \%)$. In the sensitivity analysis, the proportion of nonadherent patients decreased to 91/258 (35.3\%, 95\% CI 29.7\%-41.3\%). There was no difference in the proportion of nonadherence between regular and as-needed medications (regular: $28.0 \%, 95 \% \mathrm{CI}$ $22.1 \%-34.7 \%$ v. as needed: $31.3 \%, 95 \%$ CI $24.5 \%-39.2 \%$; $p=0.50)$.

We found a univariate positive association between nonadherence and the prescription of 2 or more medications (crude OR 1.82, 95\% CI 1.03-3.20), but this association weakened with adjustment on multivariate modeling (adjusted OR 1.71, 95\% CI 0.95-3.09, $p=0.08$ ) (Table 1). Univariate and multivariate modeling indicated trends toward associations between nonadherence and either ADREs or unplanned revisits to EDs or clinics, none of which were statistically significant. Markers of socioeconomic status were not associated with adherence. In the medication-level analysis, only antibiotics were associated with a significant reduction in the odds of nonadherence (Table 2). Asthma medications and the absence of an ADRE were associated with a trend toward a decrease in nonadherence.

\section{Discussion}

This study examined prescription-filling and adherence to ED discharge prescriptions in a Canadian urban tertiary care centre. We found high rates of failure to fill prescriptions

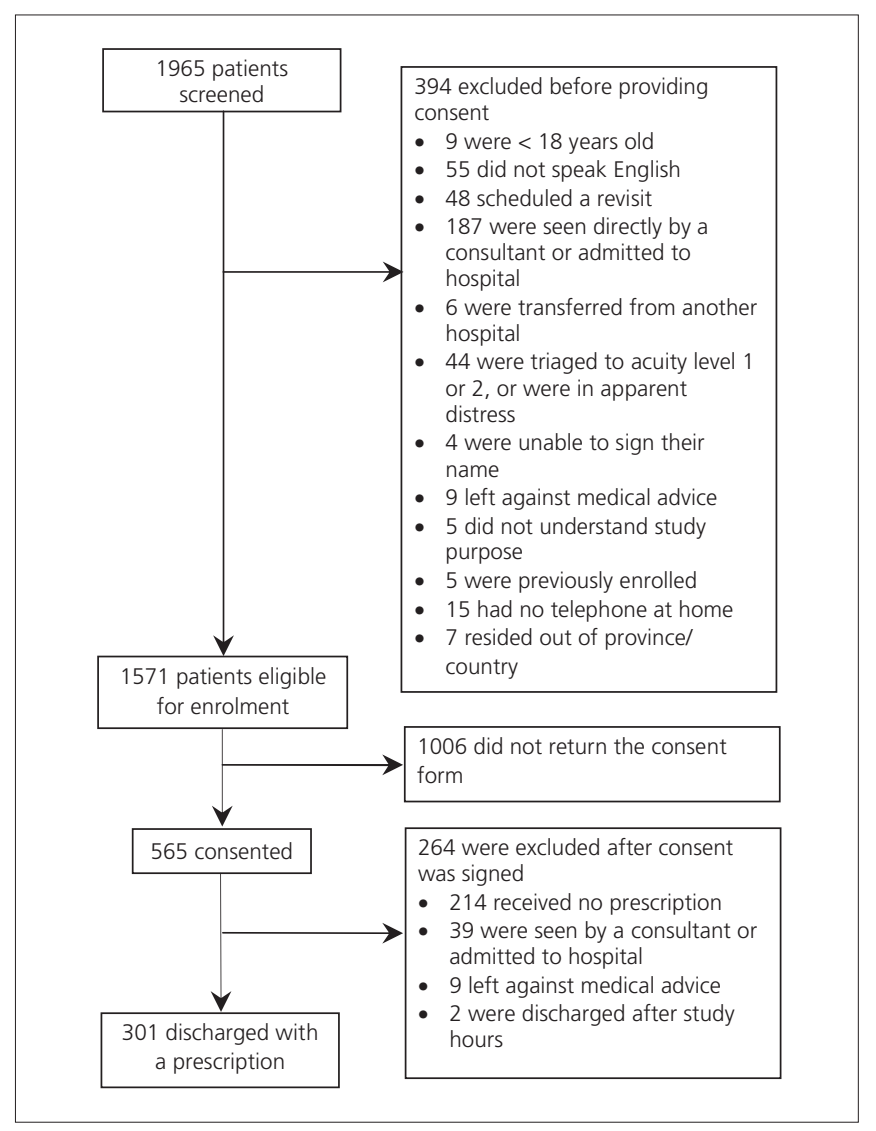

Fig. 1. Patient flow diagram.

Table 2. Crude and adjusted odds ratios of medication factors associated with nonadherence

\begin{tabular}{llcrr} 
Variable & \multicolumn{1}{c}{ Comparison } & Crude OR (95\% Cl) & Adjusted OR (95\% Cl) & $p$ value \\
\hline Opioid analgesics & Nonopioid analgesics & $0.57(0.25-1.31)$ & $0.49(0.21-1.16)$ & 0.11 \\
Anti-infectives & Nonopioid analgesics & $0.27(0.11-0.64)$ & $0.21(0.08-0.52)$ & $<0.01$ \\
CVS agents & Nonopioid analgesics & $0.43(0.09-1.98)$ & $0.29(0.05-1.65)$ & 0.16 \\
Asthma medications & Nonopioid analgesics & $0.40(0.13-1.26)$ & $0.33(0.10-1.06)$ & 0.06 \\
Gastrointestinal agents & Nonopioid analgesics & $1.62(0.41-6.34)$ & $1.68(0.39-7.25)$ & 0.49 \\
Miscellaneous agents & Nonopioid analgesics & $0.64(0.22-1.80)$ & $0.63(0.21-1.86)$ & 0.40 \\
Given a ì dose to go" & No "dose to go" & $0.85(0.48-1.49)$ & $0.74(0.40-1.36)$ & 0.33 \\
ADRE reported & No ADRE reported & $1.64(0.90-3.01)$ & $1.82(0.95-3.50)$ & 0.07 \\
\hline ADRE = adverse drug-related event; Cl = confidence interval; CVS = cardiovascular system; OR = odds ratio. & &
\end{tabular}


and nonadherence, consistent with prior studies conducted in managed care settings in the United States. We concealed the purpose of the study from participants to minimize the potential for possible enrolment bias and the Hawthorne effect. Therefore, even though we had to rely on patientreported pill counts to assess adherence, we feel that our estimates are robust.

In contrast to the United States, all patients in the study province have access to a public drug coverage plan regardless of age, employment status or health status. Public insurance deductibles are based on income, with no deductible for seniors or patients on income assistance. In addition, $40 \%$ of patients in our sample had private medical insurance. This may explain why, in contrast to studies conducted in the United States, we did not find socioeconomic factors to be important determinants for prescription-filling or adherence.

Coprescription of 2 or more medications and the occurrence of ADREs have been found to be associated with nonadherence in other health care settings. ${ }^{19,20}$ Although our findings in this area were not statistically significant, they were consistent with this trend. We believe that these modifiable factors merit further investigation in larger studies of medication adherence.

Table 3. Baseline characteristics by follow-up status

\begin{tabular}{|c|c|c|c|c|}
\hline \multirow{2}{*}{$\begin{array}{l}\text { Characteristic } \\
\text { Mean age (SD), yr }\end{array}$} & \multicolumn{2}{|c|}{$\begin{array}{l}\text { Follow-up successful, no. (\%), * } \\
\qquad n=258 \dagger\end{array}$} & \multicolumn{2}{|c|}{$\begin{array}{l}\text { Lost to follow-up, no. (\%), } \\
\qquad n=43 \dagger\end{array}$} \\
\hline & 46.3 & $(17.7)$ & 44.7 & (19.1) \\
\hline Male & 135 & $(52.3)$ & 24 & $(55.8)$ \\
\hline \multicolumn{5}{|l|}{ Highest level of education achieved } \\
\hline No formal education & 10 & $(4.0)$ & 0 & $(0.0)$ \\
\hline Primary school & 17 & (6.7) & 2 & (4.8) \\
\hline High school & 93 & $(36.8)$ & 15 & $(35.7)$ \\
\hline Diploma program & 57 & $(22.5)$ & 12 & $(28.6)$ \\
\hline University & 76 & $(30.0)$ & 13 & $(31.0)$ \\
\hline \multicolumn{5}{|l|}{ Annual income in Canadian dollars } \\
\hline$\$ 0-10000$ & 40 & $(16.7)$ & 14 & $(36.8)$ \\
\hline$\$ 10000-25000$ & 63 & $(26.3)$ & 8 & $(21.1)$ \\
\hline$\$ 25000-50000$ & 71 & $(29.6)$ & 9 & $(23.7)$ \\
\hline$>\$ 50000$ & 66 & $(27.5)$ & 7 & $(18.4)$ \\
\hline Employed & 148 & $(57.6)$ & 22 & $(52.4)$ \\
\hline $\begin{array}{l}\text { Private insurance coverage in addition to the } \\
\text { provincial plan }\end{array}$ & 107 & $(41.6)$ & 17 & $(40.5)$ \\
\hline Illicit drug use in past month & 8 & (3.1) & 5 & $(12.5)$ \\
\hline Availability of family physician & 205 & $(79.5)$ & 32 & $(76.2)$ \\
\hline Means of transportation available & 199 & (77.4) & 30 & $(71.4)$ \\
\hline Use of herbal remedies & 75 & $(29.1)$ & 12 & $(30.0)$ \\
\hline \multirow[t]{5}{*}{ Most common discharge diagnoses (\%) } & \multicolumn{2}{|c|}{ Cellulitis/abscess (13.2) } & \multicolumn{2}{|c|}{ Abdominal pain, NYD (14.0) } \\
\hline & \multicolumn{2}{|c|}{ Back pain, NYD (12.0) } & \multicolumn{2}{|c|}{ Back pain, NYD (11.6) } \\
\hline & \multicolumn{2}{|c|}{ Urinary tract infection (7.0) } & \multicolumn{2}{|c|}{ Urinary tract infection (9.3) } \\
\hline & \multicolumn{2}{|c|}{ Abdominal pain, NYD (5.4) } & \multicolumn{2}{|c|}{ Cellulitis/abscess (7.0) } \\
\hline & \multicolumn{2}{|c|}{ Soft tissue injury (4.7) } & \multicolumn{2}{|c|}{ Dental pain/infection (7.0) } \\
\hline $\begin{array}{l}\text { Median no. of discharge medications } \\
\text { prescribed (IQR) }\end{array}$ & \multicolumn{2}{|c|}{$1.0(1.0-2.0)$} & \multicolumn{2}{|c|}{$1.0(1.0-2.0)$} \\
\hline \multirow[t]{5}{*}{ Most common medications prescribed (\%) } & \multicolumn{2}{|c|}{ Acetaminophen/codeine (27.0) } & \multicolumn{2}{|c|}{ Acetaminophen/codeine (27.9) } \\
\hline & \multicolumn{2}{|c|}{ Ciprofloxacin (7.8) } & \multicolumn{2}{|c|}{ Ciprofloxacin (9.8) } \\
\hline & \multicolumn{2}{|c|}{ Cephalexin (6.4) } & \multicolumn{2}{|c|}{ Cephalexin (4.9) } \\
\hline & \multicolumn{2}{|c|}{ Hydromorphone (4.7) } & \multicolumn{2}{|c|}{ Naproxen (4.9) } \\
\hline & \multicolumn{2}{|c|}{ Naproxen (4.7) } & \multicolumn{2}{|c|}{ Prednisone (4.9) } \\
\hline \multirow[t]{3}{*}{ Most common medication classes prescribed (\%) } & Opioi & Inalgesics (34.3) & Opioid an & yesics (34.4) \\
\hline & Anti & fectives (34.0) & Anti-inf & ives (32.8) \\
\hline & Nonopi & d analgesics (8.1) & Nonopioid & lgesics (13.1) \\
\hline
\end{tabular}


Our data also suggest a possible association between nonadherence and unplanned revisits to EDs and clinics, although our study was not powered to look at this association. We feel that this potential association merits further study.

To our knowledge, this is the first ED-based study to compare self-reported measures of prescription-filling with objective data from an electronic prescription database. We found that patients overreport their prescription-filling by $7 \%$. Although we are unaware of studies that document the reliability of data for prescription-filling from this provincial prescription database, informal discussions with community pharmacists in the study area suggest it is very unlikely that prescriptions can be filled without being entered into this database, as the pharmacist would be unable to label the medication or charge the patient.

\section{Limitations}

Since this was a relatively small, single-centre study, our results and conclusions should be regarded as preliminary, and are only generalizable to similar settings and patient populations. Because of our sample size we were only able to examine a small number of potential predictors of nonadherence. Future researchers may wish to examine wait times, measures of patient satisfaction and prescriber characteristics, which have previously been examined in nonED settings..$^{20,21}$

Our study was also limited by the enrolment of a convenience sample of patients. This was done to reduce the study's impact on ED flow. In order to minimize any selection bias this strategy may have introduced, we devised an enrolment strategy that was based on enrolling patients during the times they were waiting in the ED. This strategy may have favoured enrolling patients who were waiting the longest to see an EP. We also decided a priori to exclude patients who were triaged as high acuity, as such patients

\begin{tabular}{|c|c|c|}
\hline \multirow{2}{*}{$\begin{array}{l}\text { Reasons cited for not filling } 1 \text { or more } \\
\text { prescription(s) } \\
\text { Patient felt his/her condition did not warrant } \\
\text { a prescription }\end{array}$} & \multicolumn{2}{|c|}{$\begin{array}{l}\text { No. }(\%) \\
n=29\end{array}$} \\
\hline & 7 & (24.1) \\
\hline Already had the medication at home & 5 & $(17.2)$ \\
\hline Insufficient funds available/cost too much & 3 & $(10.3)$ \\
\hline $\begin{array}{l}\text { Patient felt he/she was getting better without } \\
\text { medication }\end{array}$ & 2 & (6.9) \\
\hline $\begin{array}{l}\text { Medication doses given to the patient in the } \\
\text { ED "to go" was sufficient* }\end{array}$ & 2 & (6.9) \\
\hline Other & 10 & (34.5) \\
\hline
\end{tabular}

are less likely to be discharged, and wait less time before being seen by an EP. As a result, our findings are only generalizable to low- and moderate-acuity ED patients.

A final limitation arose from our inability to record exclusion criteria on all patients who received consent forms. Because patients were often discharged in batches at the end of shifts from 2 different locations in the ED, our RAs were not able to collect consent forms from all ineligible patients and focused their efforts on verifying discharge prescriptions on eligible patients. As a result, we were unable to provide exclusion criteria on some of these patients and cannot exclude the possibility that systematic differences existed between the 2 groups.

\section{Conclusion}

Approximately 4 of 10 patients discharged from the ED did not adhere to prescribed medication. Our results suggest that patients who are prescribed antibiotics are more likely to be adherent and that further evaluation of the associations between nonadherence, ADREs, coprescription of 2 or more medications and use of health services is warranted.

Competing interests: None declared.

\section{References}

1. Spraycar M. Stedman's medical dictionary. 26th ed. Baltimore (MD): Williams and Wilkins; 1995.

2. Chui MA, Deer M, Bennett SJ, et al. Association between adherence to diuretic therapy and health care utilization in patients with heart failure. Pharmacotherapy 2003;23:326-32.

3. Dew MA, Kormos RL, Roth LH, et al. Early post-transplant medical compliance and mental health predict physical morbidity and mortality one to three years after heart transplantation. J Heart Lung Transplant 1999;18:549-62.

4. DiMatteo MR, Giordani PJ, Lepper HS, et al. Patient adherence and medical treatment outcomes: a meta-analysis. Med Care 2002;40:794-811.

5. Gehi AK, Ali S, Na B, et al. Self-reported medication adherence and cardiovascular events in patients with stable coronary heart disease. The Heart and Soul Study. Arch Intern Med 2007;167: 1798-803.

6. Olshaker JS, Barish R, Naradzay J, et al. Prescription noncompliance: contribution to emergency department visits and cost. J Emerg Med 1999;17:909-12.

7. Hope CJ, Wu J, Tu W, et al. Association of medication adherence, knowledge, and skills with emergency department visits by adults 50 years or older with congestive heart failure. Am J Health Syst Pharm 2004;61:2043-9. 
8. Simpson SH, Eurich DT, Majumdar SR, et al. A meta-analysis of the association between adherence to drug therapy and mortality. BMJ 2006;333:15.

9. Kajioka EH, Itoman EM, Li ML, et al. Pediatric prescription pick-up rates after ED visits. Am J Emerg Med 2005;23:454-8.

10. Matsui D, Joubert GI, Dykxhoorn S, et al. Compliance with prescription filling in the pediatric emergency department. Arch Pediatr Adolesc Med 2000;154:195-8.

11. Saunders CE. Patient compliance in filling prescriptions after discharge from the emergency department. Am J Emerg Med 1987;5:283-6.

12. Thomas EJ, Burstin H, O'Neil A, et al. Patient noncompliance with medical advice after the emergency department visit. Ann Emerg Med 1996;27:49-55.

13. Dinh MM, Chu M, Zhang K. Self-reported antibiotic compliance: emergency department to general practitioner follow up. Emerg Med Australas 2005;17:450-6.

14. Lam F, Stevenson FA, Britten N, et al. Adherence to antibiotics prescribed in an accident and emergency department: the influence of consultation factors. Eur J Emerg Med 2001;8:181-8.

15. Manos D, Petrie D, Beveridge R, et al. Inter-observer agreement using the Canadian Emergency Deparment Triage and Acuity Scale. CJEM 2002;4:16-22.
16. Hohl CM, Dankoff J, Colacone A, et al. Polypharmacy, adverse drug-related events, and potential adverse drug interactions in elderly patients presenting to an emergency department. Ann Emerg Med 2001;38:666-71.

17. International drug monitoring: the role of the hospital. World Health Organ Tech Rep Ser 1966;425:5-24.

18. Canadian Pharmacists Association. Compendium of pharmaceuticals and specialties. The Canadian drug reference for health professionals. Ottawa (ON): The Association.

19. Chao J, Nau DP, Aikens JE. Patient-reported perceptions of side effects of antihyperglycemic medication and adherence to medication regimens in persons with diabetes mellitus. Clin Ther 2007;29:177-80.

20. McDonald HP, Garg AX, Haynes RB. Interventions to enhance patient adherence to medication prescriptions: scientific review. JAMA 2002;288:2868-79.

21. van Dijk L, Heerdink ER, Somai D, et al. Patient risk profiles and practice variation in nonadherence to antidepressants, antihypertensives and oral hypoglycemics. BMC Health Serv Res 2007;7:51

Correspondence to: Dr. Corinne M. Hohl, Department of Emergency Medicine, Vancouver General Hospital, 855 W 12th Ave., Vancouver BC V5Z1M9; chohl@interchange.ubc.ca 